\title{
STRATEGI PEMBELAJARAN, LOKASI SEKOLAH, DAN KEMAMPUAN GERAK DASAR SISWA SEKOLAH DASAR
}

\author{
Syahrial Bakhtiar \\ Universitas Negeri Padang, Jl. Prof. Dr. Hamka Air Tawar Padang \\ e-mail:syal_fik@yahoo.com
}

\begin{abstract}
Learning Strategies, School Locations, and Fundamental Motor Skills of Elementary School Students. This study is aimed at measuring the effects of learning strategies and school locations on students' fundamental motor skills. It is an experimental study which employs the $2 \times 2$ factorial design. The subjects of the experiment were students from elementary schools in Padang who were selected through multi stage random sampling. Data were collected using the TMGD-2 test and analyzed using the twoway ANOVA. The findings of the study show that the fundamental motor skills of the students who are taught with the Game Series Learning Strategy (GSLL) are better than those taught with the Conventional Learning Strategy (CLS). With regard to school locations, the fundamental motor skills of students in the urban areas are better than those in the suburbs. The findings also reveal an interaction of the effects of learning strategies and school locations on the students' fundamental motor skills. The students in the urban areas who learn through the GSLL have better fundamental motor skills than those who learn through the CLS. On the other hand, the students in the rural areas who learn through the GSLL demonstrate lower fundamental motor skills than those who learn through the CLS.
\end{abstract}

Keywords: learning strategy, physical education, fundamental motor skills

\begin{abstract}
Abstrak: Strategi Pembelajaran, Lokasi Sekolah, dan Kemampuan Gerak Dasar Siswa Sekolah Dasar. Penelitian ini bertujuan untuk mengukur perbedaan strategi pembelajaran dan lokasi sekolah siswa berikut interaksinya terhadap kemampuan gerak dasar. Subjek eksperimen adalah seluruh siswa SD kota Padang yang dipilih dengan multi stage random sampling dan menggunakan rancangan faktorial $2 \times 2$. Data dikumpulkan dengan tes TGMD-2 dan dianalisis dengan ANAVA dua jalur. Penelitian ini menemukan bahwa kemampuan gerak dasar siswa yang diberi perlakuan Strategi Pembelajaran Rangkaian Permainan (SPRP) lebih baik daripada siswa yang diajar dengan Strategi Pembelajaran Konvensional (SPK). Kemampuan gerak dasar siswa sekolah di kota lebih baik daripada di pinggiran kota. Terdapat interaksi pengaruh strategi pembelajaran dan lokasi sekolah terhadap kemampuan gerak dasar siswa. Kemampuan gerak dasar siswa di kota dan diberi SPRP lebih tinggi daripada siswa dengan SPK. Kemampuan gerak dasar siswa pinggiran kota dan diberi SPRP lebih rendah daripada siswa dengan SPK.
\end{abstract}

Kata kunci: strategi pembelajaran, pendidikan jasmani, kemampuan gerak dasar

Pendidikan itu bermacam-macam tetapi satu, yaitu upaya memuliakan kemanusiaan manusia (Prayitno, 2009). Sementara itu, National Association for Sport and Physical Education (NASPE) Amerika Serikat (2004) mengemukakan bahwa supaya anak-anak siap untuk memasuki abad ke-21, banyak hal harus diketahui oleh anak-anak dan apa yang dapat mereka lakukan untuk mempersiapkan diri menghadapi masa depan mereka. Pendidikan harus menjamin mereka siap mengambil peran dalam masyarakat, mampu berkompetisi secara global, serta hidup dalam keadaan sehat dan produktif. Untuk itu, paling tidak disiapkan dua jenis standar untuk pendidikan mereka, yaitu standar isi (content) dan penampilan (performance).

Standar isi didefinisikan sebagai "apa yang harus siswa ketahui dan dapat dilakukannya," sementara standar penampilan didefinisikan sebagai "seberapa baik siswa dapat melakukanya." Selanjutnya standar isi memiliki tiga tujuan, yaitu memastikan bahwa standar tersebut kompetitif secara internasional, memastikan bahwa mereka memeroleh pengetahuan yang terbaik tentang mengajar dan belajar, serta men- 
jamin mereka telah dikembangkan dalam keseluruhan aspek, dapat mengadopsi proses keterbukaan.

Untuk memberikan pengetahuan dan keterampilan dan menjamin perkembangan yang menyeluruh kepada siswa sekolah dasar, Depdiknas telah menetapkan berbagai bidang studi yang wajib diajarkan. Salah satu mata pelajaran tersebut adalah Pendidikan Jasmani. Pemberian pengetahuan dan keterampilan dalam pembelajaran pendidikan jasmani dilakukan dalam rangka memenuhi tugas perkembangan menyeluruh bagi anak.

Salah satu konsep tentang perkembangan adalah totalitas; individu merupakan suatu organisme terpadu, bukan merupakan bagian-bagian terpisah dan tidak berhubungan antara satu aspek dengan lainya (Corbin, 1980). Oleh sebab itu, untuk memungkinkan perkembangan optimal, diperlukan adanya pembinaan yang menyeluruh dan seimbang antara aspek fisik motorik, inteligensi, emosi, dan sosial anak. Mengabaikan pandangan terhadap aksi-aksi motorik sebagai bahagian dari perilaku manusia berarti mengabaikan keberadaan manusia sebagai totalitas sistem bio-psicho-sosiocultural. Dengan demikian, memerhatikan perkembangan gerak yang dilakukan melalui berbagai aktivitas motorik dalam pembelajaran pendidikan jasmani dan dalam berbagai program pelatihan bagi anak-anak tidak hanya diartikan sebagai upaya untuk menguasai keterampilan motorik olahraga, melainkan juga sebagai upaya untuk pembentukan integritas kepribadian.

Menurut Badan Standar Nasional Pendidikan (BSNP) Depdiknas (2005), Pendidikan Jasmani, Olahraga, dan Kesehatan bertujuan agar peserta didik memiliki beberapa kemampuan, di antaranya meningkatkan kemampuan dan keterampilan gerak dasar. Gerak dasar (fundamental skill) menurut Pangrazi (2007) adalah keterampilan yang membentuk dasar dari gerakan manusia. Kemampuan gerak dalam keterampilan gerak dasar (fundamental motor skill) menggambarkan derajat penguasaan keterampilan dalam menggunakan jari-jari tangan, koordinasi matatangan dan mata-kaki, tempo-keseimbangan, serta persepsi visual.

Keterampilan gerak dasar merupakan bangunan dasar untuk aktivitas fisik dan olahraga ke depannya seperti halnya abjad $\mathrm{ABC}$ dalam pengenalan huruf (Goodway dkk., 2006; Gallahue dkk., 2012). Keterampilan gerak dasar terdiri atas dua kelompok, yaitu keterampilan lokomotor dan keterampilan manipulasi. Keterampilan lokomotor adalah keterampilan seperti lari, lompat, hopping, leaping, sliding, galloping dan skipping; dengan kata lain, anak menggerakkan tubuhnya dari satu titik ke titik lain. Keterampilan manipulasi (atau disebut juga object control) berupa keterampilan melempar, menangkap, menendang, menjatuhkan dan menendang benda (objek) seperti bola atau pemukul.

Menurut Pangrazi (2007), sangat penting memelajari keterampilan gerak dasar pada usia dini karena, kalau tidak, mereka akan mengalami berbagai hambatan dalam melakukan keterampilan yang lebih sulit di kemudian hari. Terdapat dua bagian penting dalam perkembangan keterampilan gerak, yaitu memelajari berbagai keterampilan dan memelajari konsep tentang gerak. Jalal (2009) menambahkan studi-studi mengenai perkembangan otak, perilaku, motorik dan kecerdasan dalam kaitannya dengan gizi di Indonesia yang masih sedikit jumlahnya. Namun sebagaian besar studi menunjukkan peran penting zat gizi dalam pertumbuhan otak, perkembangan perilaku, motorik dan kecerdasan.

Hasil penelitian Bakhtiar (1999) menunjukkan bahwa kemampuan gerak dasar siswa SD Kecamatan Padang Utara Kota Padang banyak yang belum matang sesuai degan tingkat pertumbuhan dan perkembangannya. Untuk berlari, 52\% siswa masih tergolong tingkat dasar; melompat, 59,46\% siswa masih tergolong pemula; keseimbangan, $60,36 \%$ siswa masih tingkat dasar; dan lempar, $51,66 \%$ siswa serta menangkap, $60,66 \%$ siswa masih tergolong pemula. Dengan demikian dapat dikatakan banyak siswa yang belum baik perkembangan keterampilan geraknya.

Hasil temuan penelitian Gusril (2003) mengungkapkan bahwa sekitar 49\% anak-anak Sekolah Dasar di Kota Padang kurang mendapatkan kesempatan bermain, sehingga tingkat kesegaran jasmani mereka sebagian besar (66\%) berada dalam ketegori sedang, dan 43,5\% anak-anak memiliki kemampuan motorik sedang. Dengan demikian diperlukan upaya bagaimana supaya keseluruhan atau sebagian besar anak-anak seharusnya memiliki tingkat kesegaran jasmani dan kemampuan motorik yang baik, tidak hanya sedang.

Menurut Corbin (1980), masa anak-anak adalah masa bermain. Melalui bermain anak akan dapat mengembangkan keterampilan gerak dasar. Untuk itu, dalam pembelajaran pendidikan jasmani di Sekolah Dasar, perlu diupayakan pembelajaran yang dapat memotivasi dan menimbulkan minat anak untuk bermain sekaligus dapat mengembangkan kemampuan gerak dasar.

Berdasarkan berbagai pendapat serta studi yang yang telah dikemukakan, perlu diupayakan menemukan sebuah strategi pembelajaran yang diharapkan mampu memotivasi dan menggugah minat siswa untuk memelajari keterampilan gerak dasarnya. Melalui penelitian ini ditampilkan sebuah Strategi Pembelajaran Rangkaian Permainan (SPRP) yang bertujuan me- 
ningkatkan keterampilan gerak dasar siswa. Strategi pembelajaran rangkaian permainan (SPRP) merupakan strategi pembelajaran yang menjadikan suasana dan situasi bermain untuk menumbuhkan persaingan yang menyenangkan dalam diri seseorang yang belajar, agar mereka termotivasi dalam belajar dan berlatih dalam meraih prestasi belajar. Rangkaian permainan juga merupakan suatu sarana yang menggiring peserta agar berkompetisi untuk mencapai kemenangan. Melalui pembelajaran rangkaian permainan diperkirakan sesuai dengan karakteristik masa anak-anak tersebut, diharapkan siswa lebih giat belajar dan berlatih dan akhirnya dapat meningkatkan penguasaan keterampilan gerak dasar siswa.

Sementara itu, pada kenyataannya, letak sekolah dasar ada yang di kota dan di pinggiran kota. Perbedaan lokasi sekolah ini memiliki karakteristik tersendiri dalam kaitannya dengan perkembangan keterampilan gerak dasar siswa. Perbedaan ketersediaan sarana dan prasarana untuk bermain serta variasi dalam permainan yang berkaitan dengan aktivitas fisik di antara kedua lokasi sekolah dasar ini diduga memengaruhi keterampilan gerak dasar siswa.

Berdasarkan berbagai teori dan pendapat tersebut, maka dilakukan suatu penelitian untuk mengungkapkan penguasaan keterampilan gerak dasar siswa Sekolah Dasar di kota Padang yang lokasi sekolahnya di kota dan pinggiran kota, serta sejauh mana pembelajaran keterampilan gerak dasar yang diajarkan melalui strategi pembelajaran rangkaian permainan (SPRP) dapat meningkatkan keterampilan gerak dasar siswa sekolah dasar.

Penelitian ini memiliki lima tujuan, yaitu untuk mengetahui (1) perbedaan keterampilan gerak dasar siswa antara kelompok siswa yang diberi perlakuan strategi pembelajaran rangkaian permainan (SPRP) dengan kelompok siswa yang diberikan perlakuan pembelajaran konvensional (SPK), (2) perbedaan keterampilan gerak dasar siswa antara kelompok siswa yang lokasi sekolahnya di kota dan kelompok siswa yang lokasi sekolahnya di pinggiran kota, (3) pengaruh interaksi strategi pembelajaran dan lokasi sekolah terhadap keterampilan gerak dasar siswa, (4) perbedaan keterampilan gerak dasar siswa antara kelompok siswa yang lokasi sekolahnya di kota yang diberi perlakuan pembelajaran rangkaian permainan (SPRP) dengan yang diberi perlakuan pembelajaran konvensional (SPK), (5) perbedaan keterampilan gerak dasar siswa antara kelompok siswa yang lokasi sekolahnya di pinggiran kota yang mendapatkan perlakuan pembelajaran konvensional (SPK) dengan perlakuan strategi pembelajaran rangkaian permainan (SPRP).

\section{METODE}

Penelitian ini menggunakan metode eksperimen dengan rancangan faktorial $2 \times 2$, seperti pada Tabel 1 . Penelitian ini menggunakan subjek siswa Sekolah Dasar Negeri Kota Padang bulan Januari hingga Juni 2010. Perlakuan penelitian dalam hal ini adalah pelaksanaan eksperimen dengan menggunakan strategi pembelajaran rangkaian permainan (SPRP) di satu kelompok dan strategi pembelajaran konvensional (SPK) di kelompok yang lain selama 6 bulan. Rangkaian permainan yang adalah rangkaian pembelajaran yang diurutkan dari bentuk-bentuk permainan yang sederhana dan mudah ke urutan yang lebih sulit serta kompleks menuju kepada permainan yang sebenarnya, dan pembelajarannya dari keseluruhan ke bagianbagian. Untuk mengembangkan bentuk permainan dapat dilakukan dengan mengonstruksi dan mengubah peraturan-peraturan permainan itu sendiri sesuai dengan tujuan yang ingin dicapai.

Populasi penelitian ini adalah seluruh murid sekolah dasar (SD) Kota Padang yang lokasi sekolahnya di kota maupun di desa. Sampel diambil secara multi stage random sampling yaitu sampel diambil secara bertahap. Pengambilan sampel wilayah (lokasi sekolah) dilakukan secara cluster. Didapatkan jumlah sampel 720 orang.

Untuk mendapatkan data penelitian digunakan tes kemampuan gerak dasar Test of Groos Motor Development-2 (TGMD-2) yang disusun oleh Ulrich. Menurut Goodway \& Branta (2003), Test of Groos Motor Development-2 (TGMD-2) yang disusun oleh Ulrich telah terpilih untuk mengukur kemampuan keterampilan gerak dasar (fundamental motor skill performance) dan sudah terbukti validitas dan reliabilitasnya.

Rerata tes-retes yang digunakan untuk mengukur reliabilitas menunjukkan koefesien sebesar 0,96 untuk keterampilan locomotor dan 0,97 untuk keterampilan object control. Validitas isi (content validity) diperoleh melalui penilaian tiga orang ahli, dan validitas konstruk (construct validity) ditentukan melalui analisis faktor.

Tabel 1. Rancangan Eksperimen Faktorial 2x2 dan Jumlah Subjeknya

\begin{tabular}{cccc}
\hline $\begin{array}{c}\text { Strategi } \\
\text { Pembelajaran } \\
\text { Lokasi Sekolah }\end{array}$ & $\begin{array}{c}\text { Rangkaian } \\
\text { Permainan } \\
\left(\mathbf{A}_{1}\right)\end{array}$ & $\begin{array}{c}\text { Konvensional } \\
\left(\mathbf{A}_{2}\right)\end{array}$ & Jumlah \\
\hline Kota $\left(\mathrm{B}_{1}\right)$ & $\mathrm{A}_{1} \mathrm{~B}_{1}$ & $\mathrm{~A}_{2} \mathrm{~B}_{1}$ & $\mathrm{~B}_{1}$ \\
& 180 orang & 180 orang & 360 orang \\
Pinggiran Kota & $\mathrm{A}_{1} \mathrm{~B}_{2}$ & $\mathrm{~A}_{2} \mathrm{~B}_{2}$ & $\mathrm{~B}_{2}$ \\
$\left(\mathrm{~B}_{2}\right)$ & 180 orang & 180 orang & 360 orang \\
Jumlah & $\mathrm{A}_{1}$ & $\mathrm{~A}_{2}$ & Total \\
& 360 orang & 360 orang & 720 orang \\
\hline
\end{tabular}


Tabel 2. Ringkasan Anava Dua Jalur Keterampilan Gerak Dasar

\begin{tabular}{|c|c|c|c|c|c|c|c|}
\hline \multirow{2}{*}{ Sumber Varians } & \multirow{2}{*}{$\mathrm{dk}$} & \multirow{2}{*}{$\begin{array}{l}\text { Jumlah Kuadrat } \\
\qquad(\mathrm{JK})\end{array}$} & \multirow{2}{*}{$\begin{array}{c}\text { Rerata Jumlah } \\
\text { Kuadrat } \\
\text { (RJK) }\end{array}$} & \multirow{2}{*}{$\mathrm{F}_{\text {hitung }}$} & \multirow[b]{2}{*}{$\alpha=0,05$} & \multirow[b]{2}{*}{$\alpha=0,01$} & \multirow{2}{*}{ Kesimpulan } \\
\hline & & & & & & & \\
\hline Strategi Pembelajaran & 1 & 5088.05 & 5088.05 & $33.66^{* *}$ & 3,85 & 6,68 & Sangat Sig \\
\hline Lokasi Sekolah & 1 & 657.42 & 657.42 & $4.35^{*}$ & 3,85 & 6,68 & Sig \\
\hline Inter $\mathrm{AB}$ & 1 & 18768.02 & 18768.02 & $124.16^{* *}$ & 3,85 & 6,68 & Sangat Sig \\
\hline Kekeliruan Dalam & 716 & 108227.83 & 151.16 & - & - & - & \\
\hline
\end{tabular}

TGMD-2 mengevaluasi penampilan keterampilan lokomotor, yang terdiri dari lari (run), gallop, hop, leap, horizontal jump, dan slide. Gerakan object control terdiri dari striking, stationary dribble, catch, kick, overhand throw, dan underhand roll.

Sebelum data dianalisis, dilakukan pengujian persyaratan analisis pada data yang diperoleh sebagai prasyarat penggunaan teknik analisis statistik. Selanjutnya baru dilakukan pengujian hipotesis. Uji persyaratan analisis yang digunakan adalah uji normalitas dengan uji Liliefors dan uji homogenitas varian dengan uji Bartlett. Pengujian persyaratan analisis data menunjukkan bahwa kelompok-kelompok data dalam penelitian ini berasal dari populasi yang berdistribusi normal dan memiliki varians yang homogen. Dengan demikian maka persyaratan normalitas dan homogenitas data terpenuhi sehingga dapat digunakan analisis varian dalam pengujian hipotesis penelitian.

Pengujian hipotesis penelitian ini menggunakan teknik analisis varian (Anava) dua jalur dengan rancangan faktorial $2 \times 2$. Taraf kepercayaan yang digunakan untuk pengujian tersebut adalah $\alpha=0,05$. Apabila pengujian hipotesis menunjukkan hasil signifikan, dilakukan uji Tukey untuk melihat efek interaksi yang lebih baik.

\section{HASIL DAN PEMBAHASAN}

Pengujian hipotesis dalam penelitian ini dilakukan dengan menggunakan analisis varian melalui pengujian dengan menggunakan analisis varian dua jalur, seperti yang dirangkum pada Tabel 2.

Dengan adanya interaksi dan signifikannya pengaruh utama antara bentuk strategi pembelajaran dan lokasi sekolah dalam analisis varian di atas, pengujian dilanjutkan dengan menggunakan uji Tukey antara pasangan data guna menentukan rerata kelompok mana yang lebih tinggi antara dua kelompok data yang dipasangkan (Tabel 3).

Dari hasil perhitungan Anava terlihat bahwa perbedaan keterampilan gerak dasar antara kelompok siswa yang diberi perlakuan pendekatan pembelajaran rangkaian permainan dengan kelompok siswa yang diberi perlakuan pendekatan pembelajaran konvensional terbukti sangat signifikan. Dari uji Tukey, maka didapat perbedaan yang sangat signifikan antara keterampilan gerak dasar kelompok siswa yang diberi perlakuan pendekatan pembelajaran rangkaian permainan SPRP (skor lebih tinggi) dengan kelompok siswa yang diberi perlakuan pendekatan pembelajaran konvensional (SPK) (skor lebih rendah).

Tabel 3. Hasil Uji Tukey antara Kelompok Data

\begin{tabular}{|c|c|c|c|c|c|}
\hline \multirow[b]{2}{*}{ Kelompok } & \multirow[b]{2}{*}{$\mathrm{n}$} & \multirow[b]{2}{*}{ Qhitung } & \multicolumn{2}{|c|}{$\mathrm{Q}_{\text {tabel }}$} & \multirow[b]{2}{*}{ Kesimpulan } \\
\hline & & & $\begin{array}{c}\alpha= \\
0,05\end{array}$ & $\begin{array}{c}\alpha= \\
0,01\end{array}$ & \\
\hline$A_{1}-A_{2}$ & 720 & $11,60 * *$ & 2,77 & 3,64 & $\begin{array}{c}\text { Sangat } \\
\text { Sigifikan }\end{array}$ \\
\hline $\mathrm{B}_{1}-\mathrm{B}_{2}$ & 720 & $4,17 * *$ & 2,77 & 3,64 & $\begin{array}{c}\text { Sangat } \\
\text { Signifikan }\end{array}$ \\
\hline $\begin{array}{c}\mathrm{A}_{1} \mathrm{~B}_{1}- \\
\mathrm{A}_{2} \mathrm{~B}_{1}\end{array}$ & 360 & $23,96^{* *}$ & 2,77 & 3,64 & $\begin{array}{c}\text { Sangat } \\
\text { Signifikan }\end{array}$ \\
\hline$A_{1} B_{2}-A_{2} B_{2}$ & 360 & $7,55^{* *}$ & 2,77 & 3,64 & $\begin{array}{c}\text { Sangat } \\
\text { Signifikan }\end{array}$ \\
\hline
\end{tabular}

Adisasmita (1989) menasehatkan untuk menggunakan metode penemuan dan permainan untuk menimbulkan suasana pembelajaran yang menyenangkan, di samping metode pujian umum dan kritikan pribadi. Selanjutnya dikemukakan aliran pragmatis percaya bahwa permainan harus diselenggarakan agar keinginan moral dan penilaian etik dapat berkembang. Perhatian yang besar dari siswa adalah penting, siswa akan belajar tentang suatu yang menarik. Oleh sebab itu, tenaga dan waktu perlu seluas-luasnya diberikan untuk memotivasi siswa. Dikemukakan pula bahwa aliran filsafat kemanusiaan menganjurkan pemakaian situasi sebagai proses motivasi. Permainan merupakan suatu sarana yang menggiring peserta untuk berkompetisi, misalnya untuk mencapai kemenangan, yang peraturannya telah disepakati terlebih dahulu. Dua hal yang harus ada dalam suatu permainan, yaitu sifat kompetitif dan seperangkat peraturan permainan (Khakim dkk., 2014; Prambudi dkk., 2014). Karena siswa ingin selalu meraih kemenangan, 
maka ia berlomba-lomba untuk menguasai keterampilan bermain dengan baik atau menampilkan kemampuannya dengan sungguh-sungguh (Hendrawan dkk., 2014). Para siswa tidak saja terlibat secara fisik, tetapi juga secara kognitif, dan suasana kelas menggembirakan, akhirnya siswa memeroleh kegiatan belajar (learning activity) dan selanjutnya menjadi pengalaman belajar (learnng experience) yang bermakna dalam memelajari keterampilan gerak.

Keterampilan gerak dasar kelompok siswa yang diberi perlakuan strategi pembelajaran rangkaian permainan lebih tinggi daripada kelompok siswa yang diberi perlakuan strategi pembelajaran konvensional. Hal ini disebabkan karena dengan strategi pembelajaran rangkaian permainan siswa lebih aktif berlatih dan untuk meraih keterampilan gerak waktu aktif berlatih adalah hal yang utama.

Dari hasil perhitungan Anava terlihat bahwa nilai $F_{\text {hitung }}=4,35>F_{\text {tabel }(\alpha=0,05 ; 720)}=3,85$. Hal itu berarti perbedaan keterampilan gerak dasar antara kelompok siswa yang memiliki lokasi sekolah di kota dengan kelompok siswa yang memiliki lokasi sekolah di desa terbukti signifikan pada $\alpha=0,05$. Uji Tukey menunjukkan nilai $\mathrm{Q}_{\text {hitung }}=4,17>\mathrm{Q}_{\text {tabel }(\alpha=0,05 ; 720)}=3,64$. Ini berarti terdapat perbedaan yang signifikan antara keterampilan gerak dasar kelompok siswa yang memiliki lokasi sekolah di kota (skor lebih tinggi) dengan kelompok siswa yang memiliki lokasi sekolah di pinggiran kota (skor lebih rendah).

Temuan tersebut sejalan dengan beberapa keadaan yang ditemui diantaranya adalah sebagai berikut. Siswa di kota lebih memiliki peluang dan kesempatan untuk sosialisasi berbagai permainan, tersedianya guru olahraga yang membimbing pembelajaran keterampilan gerak, relatif lebih mudah mendapatkan sarana dan prasarana olahraga. Sebaliknya, siswa di pinggiran kota kurang mendapatkan kesempatan untuk melakukan aktivitas fisik, disebabkan ruang terbuka yang semakin sulit ditemui, secara turun temurun hanya memainkan permainan tertentu, kurang bervariasi dalam arti hanya melatih keterampilan gerak dasar tertentu, siswa laki-laki lebih dominan dalam gerakan kaki, lari, lompat, dan sebagainya; kurang sekali yang terlibat dengan permainan yang menggunakan tangan. Siswa perempuan lebih terbatas lagi karena hambatan sosial budaya, kurang mendaparkan kesempatan bermain, hal ini sesuai dengan hasil penelitian yang dilakukan Gusril (2003) yang mengungkapkan sebagian besar anak-anak di kota Padang rendah sekali kesempatannya dalam bermain. serta tidak semua sekolah memiliki guru Pendidikan Jasmani yang berkualitas.
Hasil pengujian pengaruh interaksi berdasarkan perhitungan Anava terlihat bahwa nilai $\mathrm{F}_{\text {hitung }}=$ $124,16>F_{\text {tabl }(\alpha=0,01 ; 1 / 720)}=6,68$. Hal ini berarti terdapat interaksi pengaruh pemberian bentuk pendekatan pembelajaran dengan lokasi sekolah. Keterampilan gerak dasar siswa yang lokasi sekolahnya di kota tertinggi diperoleh pada pemberian strategi pembelajaran rangkaian permainan, sedangkan siswa yang lokasi sekolahnya di desa memeroleh keterampilan gerak dasar tertinggi pada pemberian perlakuan pendekatan pembelajaran konvensional. Hal ini menunjukkan bahwa terdapat interaksi pengaruh strategi pembelajaran dalam pembelajaran keterampilan gerak dasar dan lokasi sekolah. Goodway \& Branta (2003) melalui studinya mengungkapkan secara keseluruhan intervensi dan semua pendekatan menunjukkan keberhasilan dalam meningkatkan keterampilan gerak dasar anak yang kurang beruntung. Hal yang penting adalah dalam semua intervensi, instruksi yang berkualitas diberikan sejalan dengan pemberian kesempatan berlatih sebesar mungkin, peralatan mencukupi serta tugas yang bersifat individual berdasarkan kebutuhan perkembangan anak. Valentini dan Rudisill (2004) serta Robinson dan Goodway (2009) mengemukakan bahwa pendekatan pembelajaran gerak dasar bagi anak melalui "penguasaan iklim motivasi" dengan memberikan anak kebebasan memilih tugas dan aktivitas yang mereka sukai akan mampu meningkatkan kemampuan gerak dasar secara signifikan.

Dari hasil perhitungan uji Tukey antara kelompok siswa yang memiliki lokasi sekolah di kota dan diberi perlakuan pendekatan pembelajaran rangkaian permainan dan pembelajaran diperoleh nilai $\mathrm{Q}_{\text {hitung }}=$ $23,96>\mathrm{Q}_{\text {tabel }(\alpha=0,01 ; 360)}=3,64$ yang berarti terdapat perbedaan pengaruh yang sangat signifikan di mana keterampilan gerak dasar kelompok siswa yang memiliki lokasi sekolah di kota dan diberi perlakuan pendekatan pembelajaran rangkaian permainan ternyata lebih tinggi daripada keterampilan gerak dasar kelompok siswa yang diberi perlakuan pendekatan pembelajaran konvensional.

Metode pembelajaran permainan menuntut anak untuk ikut aktif dalam menjalankannya, dan pendidik cenderung hanya sebagai pengarah dan fasilitator. Siswa berperan utama dalam menjalankan kegiatan pembelajaran. Siswa dituntut untuk mencari strategi bagaimana memenangkan permainan tersebut. Selain itu, siswa didorong untuk melakukan suatu pekerjaan yang mengarah pada tujuan yang hendak dicapai dan melatih tanggung jawab (Suparno, 2013). Dengan demikian siswa akan banyak melakukan tindakan yang dapat mempercepat proses keterampilan gerak dasar anak. 
Siswa di kota yang melakukan pembelajaran secara konvensional, walaupun tersedia fasilitas yang memadai, mereka tidak akan bisa berkembang dengan baik jika mereka dihadapkan dengan metode pembelajaran yang membuat mereka pasif. Pembelajaran konvensional hanya menuntut keaktifan dan kreativitas guru, sedangkan siswa sebagai objek yang menerima meskipun fasilitas yang tersedia cukup. Dengan banyaknya fasilitas yang tersedia, kondisi masyarakat yang homogen, sumber informasi yang banyak serta heterogennya masalah sosial siswa akan terbantu dalam proses kematangan, ditambah lagi dengan metode pembelajaran permainan yang sangat membantu memercepat proses gerak dasar pada anak. Jadi dapat disimpulkan bahwa metode pembelajaran permainan terhadap anak yang tinggal di kota akan semakin memercepat proses peningkakan keterampilan gerak dasar pada anak, dan sebaliknya jika siswa di kota tidak pernah diberikan pembelajaran dengan strategi pembelajaran rangkaian permainan, maka akan semakin memerlambat proses peningkatan keterampilan gerak dasar anak.

Dengan demikian, keterampilan gerak siswa yang sekolahnya berlokasi di kota apabila diberikan rangkaian permainan lebih baik daripada diberi strategi pembelajaran konvensional.

Dari hasil perhitungan uji Tukey antara kelompok siswa yang memiliki lokasi sekolah di desa yang diberi perlakuan pendekatan pembelajaran rangkaian permainan dengan pendekatan pembelajaran konvensional diperoleh nilai $\mathrm{Q}_{\text {hitung }}=7,55>\mathrm{Q}_{\text {tabel }(\alpha=0,01 ; 360)}$ $=3,64$. Dengan demikian terdapat perbedaan pengaruh yang sangat signifikan di mana keterampilan gerak dasar kelompok siswa yang memiliki lokasi sekolah di desa dan diberi perlakuan pendekatan pembelajaran rangkaian permainan lebih rendah daripada keterampilan gerak dasar kelompok siswa yang diberi perlakuan pendekatan pembelajaran bentuk konvensional.

Keterbatasan yang dimiliki oleh daerah pinggiran kota tentu saja memberikan dampak terhadap perkembangan anak di pinggiran kota, termasuk para siswa yang ada di pinggiran kota, karena tingkat perkembangan anak juga dipengaruhi oleh lingkungan sekitarnya, baik itu faktor alami maupun faktor sosial yang terjadi di pinggiran kota. Dengan demikian, guru di pinggiran kota dituntut mencermati berbagai keunggulan dan keterbatasan siswa, yaitu dengan memanfaatkan berbagai keadaan agar anak-anak lebih aktif dan menyenangi aktivitas bermain. Guru dituntut aktif dan kreatif dalam merancang bentuk-bentuk permainan untuk mengembangkan semua unsur kete- rampilan gerak dasar, sehingga siswa tergugah dan timbul motivasinya untuk mengembangkan keterampilan mereka. Oleh sebab itu, dengan kurang berhasilnya strategi pembelajaran rangkaian permainan dalam mengembangkan keterampilan dasar bagi siswa, maka faktor guru sangat menentukan untuk keberhasilan penerapan strategi pembelajaran rangkaian permainan di masa yang akan datang. Dengan demikian siswa yang bertempat tinggal di pinggiran kota dan sekolah berlokasi di pinggiran kota dan cenderung lebih senang dengan pembelajaran yang selama ini telah diajarkan guru atau secara konvensional perlu dilakukan pendekatan yang lebih intensif dan terbuka agar siswa mau melakukan perubahan serta memberikan pemahaman tentang pentingnya memelajari semua unsur keterampilan gerak dasar, sehingga mereka merasa perlu melakukan berbagai permainan lainnya.

\section{SIMPULAN}

Terdapat perbedaan keterampilan gerak dasar antara kelompok siswa yang diberi perlakuan strategi pembelajaran rangkaian permainan dengan kelompok siswa yang diberi perlakuan pembelajaran konvensional; siswa yang diberi pembelajaram gerak dasar melalui strategi pembelajaran rangkaian permainan menunjukkan keterampilan yang lebih baik daripada yang mendapatkan pembelajaran dengan strategi pembelajaran konvensional. Terdapat perbedaan keterampilan gerak dasar antara siswa yang lokasi sekolahnya di kota dengan siswa yang lokasi sekolahnya di desa; keterampilan gerak dasar siswa yang berlokasi sekolah di kota lebih baik daripada siswa yang berlokasi sekolah di desa. Terdapat pengaruh interaksi strategi pembelajaran dan lokasi sekolah terhadap keterampilan gerak dasar siswa. Terdapat perbedaan keterampilan gerak dasar antara siswa yang lokasi sekolahnya di kota dan diberi perlakuan startegi pembelajaran rangkaian permainan dengan siswa yang diberi perlakuan pembelajaran konvensional; keterampilan gerak dasar siswa yang diberikan pembelajaran melalui strategi pembelajaran rangkaian permainan lebih tinggi daripada siswa yang mendapatkan pembelajaran konvensional. Terdapat perbedaan keterampilan gerak dasar antara siswa yang lokasi sekolahnya di desa dan diberi perlakuan pembelajaran rangkaian permainan dengan yang diberi perlakuan pembelajaran konvensional; keterampilan gerak dasar siswa yang diberi strategi pembelajaran rangkaian permainan lebih rendah daripada siswa yang diberi pembelajaran gerak dasar melalui pembelajaran konvensional. 


\section{DAFTAR RUJUKAN}

Adisasmita. 1989. Olahraga Pilihan Atletik. Jakarta: Proyek Pengembangan Lembaga Pendidikan Tenaga Pendidikan, Departemen Pendidikan dan Kebudayaan.

Badan Standar Nasional Pendidikan (BSNP) Depdiknas. 2005. Pembelajaran Pendidikan Jasmani. Jakarta: Depdiknas.

Bakhtiar, S. 1999. Kemampuan Gerak Dasar Pelajar Sekolah Dasar Negeri Kota Padang. Laporan Penelitian tidak diterbitkan. Padang: IKIP Padang.

Corbin, C.B. 1980. A Textbook of Motor Development. Iowa: WmC. Browen Company Publisher.

Gallahue, D.L., Ozmun, J.C., \& Goodway, J.D. 2012. Understanding Motor Development: Infants, Children, Adolescent and Adults ( $7^{\text {th }}$ ed). Boston: McGrawHill.

Goodway, J. D. \& Branta, C.F. 2003. Influence of a Motor Skill Intervention on Fundamental Motor Skill Development of Disadvantaged Preschool Children. Research Quarterly for Exercise and Sport, 74 (1): 36-47.

Goodway, J.D., Robinson, L.E., \& Crowe, H. 2006. Developmental Delay in Fundamental Motor Skill Development of Ethnically Diverse and Disadvantaged Prescoolers. Research Quarterly for Exercise and Sport, 81 (1): 17-25.

Gusril. 2003. Faktor-Faktor yang Memengaruhi Kemampuan Motorik Siswa Sekolah Dasar Negeri Kotamadya Padang. Disertasi tidak diterbitkan. Jakarta: PPS Universitas Negeri Jakarta.

Hendrawan, D., Januarto, O.B., \& Purnami, S. 2014. Peningkatan Pembelajaran Gerak Dasar Lempar dengan Menggunakan Metode Bermain pada Siswa Kelas V SDN Cowek II Kecamatan Purwodadi Kabupaten Pasuruan. Pendidikan Jasmani, 24 (1): 80-85.
Jalal, F. 2009. Pengaruh Gizi dan Stimulasi Psikososial terhadap Pembentukan Kecerdasan Anak Usia Dini: Agenda Pelayanan Tumbuh Kembang Anak Holistik-Integratif. Pidato Pengukuhan sebagai Guru Besar Ilmu Gizi Universitas Andalas, Padang, 25 April.

Khakim, L., Mu'arifin, \& Sudjana, I N. 2014. Peningkatan Keaktifan Siswa Kelas V Sekolah Dasar dalam Pembelajaran Variasi Gerak Dasar Atletik dengan Metode Bermain. Pendidikan Jasmani, 24 (1): 1-5.

National Association for Sport and Physical Education. 2004. Moving Into the Future: National Standards for Physical Education (2nd ed.). Reston, VA: Author.

Pangrazi, Robert. 2007 Dynamic Physical Education for Elementary School Children (15th ed.). San Francisco: Pearson Benjamin Cummings.

Prambudi, E.S., Winarno, M.E., \& Saichudin. 2014. Pengembangan Model Permainan "Take and Run" dalam Pembelajaran Lari Jarak Pendek Kelas X SML. Pendidikan Jasmani, 24 (1): 6-16.

Prayitno. 2009. Pendidikan: Dasar Teori dan Praksis Jilid I. Padang: UNP Press.

Robinson, L.E. \& Goodway, J.D. 2009. Instuctional Climates in Preschool Children Who are at Risk. Part I: Object Control Skill Development. Research Quarterly for Exercise \& Sport, 80 (3): 533-542.

Suparno. 2013. Dampak Permainan Bowling Tiruan terhadap Kecakapan Motorik Anak Terbelakang Mental Usia Dini. Jurnal Ilmu Pendidikan, 19 (2): 155-160.

Valentini, N.C. \& Rudisill, M.E. 2004. An Inclusive Mastery Climate Intervention and the Motor Skill Development of Children with and without Disabilities. Adapted Physical Activy Quarterly, 2004 (21): 330-347. 